\title{
Três variações sobre o amor na filosofia de Nietzsche
}

\author{
Jelson R. de Oliveira*
}

Resumo:Opresenteartigotemcomoobjetivoanalisartrês aspectosdotemadoamornaobradeFriedrichNietzsche. Paratanto,partededoispressupostos:[1]osentimentodo amordeveserentendidocomopartedoprojetodecríticaà metafísicaeaosidealismospresentesnamoral,nareligião enaarte; ecomoconsequência,[2] comocrítica àsnoções doamorqueremeteàtradiçãosocrático-platônico,judaico-cristãemoderna.Paratanto, ostrêsaspectos daíderivados,mostramqueoamoremNietzschel]nãoéfalta,[2] nemnegaçãodesi,[3]nemestábaseadonaideia deposse; muitopelocontrário,[1] amoréexuberância,[2]depende dafruiçãodesie[3] estábaseadonas diferenças próprias edesigualdadesnaturaisentreosindivíduos. Talprocedimentoanalíticochegaà afirmaçãoda amizadecomoamor superior, cujo conteúdo remente a um sentimento de homensnobres, precisamenteaquiloquesepoderiachamar, em Nietzsche, de um grande amor.

Palavras-chave:amor,egoísmo,grandeamor, afirmação de si, solidão.

\section{Introdução}

"A exigência de ser amado é a maior das pretensões"

(Nietzsche, HH, 523)

\footnotetext{
* Professor do Programa de Pós-Graduação em Filosofia da PUCPR, Brasil. Correio eletrônico: jelsono@yahoo.com.br

ORCID: https://orcid.org/0000-0002-2362-0494
}

Cad. Nietzsche, Guarulhos/Porto Seguro, v.41, n.3, setembro-dezembro $2020 \mid 79$ 
Embora não esteja em sua órbita central, o tema do amor é um dos mais ricos e mais instigantes da filosofia de Nietzsche. Disperso ao longo de toda sua obra, sua importância teórica ganha destaque no âmbito de sua crítica à metafísica e aos idealismos, precisamente a partir do segundo período de sua produção filosófica (1876), no contexto de reflexão sobre os sentimentos morais e a análise psicológica da moralidade. Nesse sentido, devemos partir do fato de que a análise do amor está fundada, precisamente, na crítica ao romantismo e à idealização do amor ${ }^{1}$ O tema é, por isso, parte central do projeto de Humano, demasiado Humano, livro no qual, como se sabe, Nietzsche se utiliza da ciência para combater a metafísica presente em três âmbitos da cultura: a religião, a moral e a arte. Vários textos e passagens em relação ao amor, presentes nesta obra publicada em 1878, dizem respeito ao fato de que o amor precisa ser retirado das malhas metafísicas da idealização: eis por que Nietzsche dirige sua crítica ao modo como o amor foi tratado, seja do ponto de vista de sua concepção teórica na filosofia, na moral e na religião, seja do ponto de vista das suas inclinações institucionais, como é o caso do matrimônio.

Vale notar, como bem o faz Ernani Chaves que o tema do amor em Nietzsche está relacionado aos moralistas franceses e também à ópera de Bizet ${ }^{2}$, que servia de contraposição a Wagner: "Stendhal, não por acaso, é o autor do De l'amour, obra que para Nietzsche representaria uma verdadeira 'suma' da análise das pai-

1 Em referência a Musset e Wagner, Nietzsche escreve sobre os "homens de 1830", precisamente aqueles que "impulsionaram uma absurda divinização do amor" (Nachlass/FP, 11 [34], 1887-1888, KSA 13.19).

2 Carmen é assumida por Nietzsche como uma espécie de alternativa antirromântica. A respeito da obra, Nietzsche escreve, entusiasmado: "Finalmente o amor, o amor retraduzido em natureza! Não o amor de uma 'virgem sublime’! Nenhum sentimentalismo de Senta! Mas o amor como fado, como fatalidade, cínico, inocente, cruel - e precisamente nisso natureza! O amor que em seus meios é a guerra, e no fundo o ódio mortal dos sexos! - Não sei de caso em que a ironia trágica que constitui a essência do amor seja expressa de maneira tão rigorosa, numa fórmula tão terrível, como no último grito de Don José, que conclui a obra" (WA/CW 2, KSA 6.15).

80| Cad. Nietzsche, Guarulhos/Porto Seguro, v.41, n.3, setembro-dezembro 2020 
xões, em conexão com os moralistas franceses, que ele também lia com grande entusiasmo nesta mesma época" (Chaves, 2013, p. 49). Em uma nota de seu artigo, Chaves ainda destaca:

Lembremos, por exemplo, que grande parte das Maximes, de La Rochefoucauld é dedicada às paixões, em especial ao amor. Nietzsche possuía três diferentes edições das obras de La Rochefoucauld na sua Biblioteca pessoal: Maximen und Reflexionen/deutsch v. Friedrich Hörlek. - Leipzig: Reclam, o. J.; Réflexions, sentences et maximes morales/ précédées d une notice par Ch. A. Saint-Beuve e Sätze aus der höheren Welt- und Menschenkunde/deutsch hrsg. V. Friedsrich Schulz. - Breslau, 1793. (Chaves, 2013, p. 49).

Merimée, Standhal e os moralistas franceses, nesse caso, são ocasião de consolidação da ruptura com Wagner e Schopenhauer, portanto, com sua visão metafísica da arte, presente no primeiro período de sua produção filosófica.

Nessaperspectiva,Nietzschesecontrapõeatrêstradições do amor:[1]primeiro, àtradiçãosocrático-platônica,principalmente no que tange àideia de amor como castigo e comofalta, tal como se encontra emObanquete, porexemplo;[2] segundo, àtradiçãocristã, quetransformou oamor emcaridade,compaixãoebenevolência,valorescentrados na abnegaçãodesi;e, [3] emterceirolugar, à ideia moderna de amor, baseada na concepção de igualdade de direitos, que passou a orientar a vida das famílias. Desse pontode vista,para Nietzsche, [1] oamor nãoéfalta,[2]nemnegaçãodesi, [3] nem estábaseado naideia de posse. Pelo contrário, [1] amoré exuberância, [2]dependedacapacidadedefruiçãodesie[3]está baseadonas diferençaspróprias edesigualdadesnaturais entreos indivíduos, cujo símbolo é a amizade.

\section{Amor como fruição de si}

Sena passagemfamosad'Obanquete os deuses castigaramos 
sereshumanos dividindo-osemisturando-osparaquepassassem a vida em carência efalta, tentandoencontrar a sua outra metade quelhesfaltava ${ }^{3}$, paraNietzscheoamordependeprimeirodeuma capacidadedeautocompletudeeautoafirmação:apenasindivíduos plenos de si podem amar. O amor nãoé outra coisa que um derramamento, uma espécie de luxo e de dádiva daquilo que cada indivíduo conquistoupore para simesmo equer partilhar, alegremente, com umoutro. Nessecaso, nãohá nada decarência, mas muito pelocontrário, de plenitude. Quanto mais pleno de si,mais capaz deamarseráumindivíduo.Oexemplo, paradoxal,seria opróprio Jesus: nasuareleitura da "psicologiadoredentor" propostaem $O$ anticristo, Nietzsche deixa entrever a ideia de que Jesus poderia estar entre aqueles indivíduos que viam a si mesmos com tal plenitude,confiançaealegria, quenãoteriaencontradojeitomelhor paraexpressarissodoquedizendo"EusouDeus", ou "Eusoufilho deDeus". E foi justamente esse sentimento que o levou ao grande amorparacomoshomens, algoqueteriasidofortementedeturpado pelocristianismo, apartirdePaulo.Porisso,o "célebrefundador do Cristianismo" (MA I/HH I, 144, KSA 2.140) estava entre as exceções à descriçãopropostapor Nietzschenoterceirocapítulo, Sobre a vida religiosa, de Humano, demasiado humano.

3 "Em primeiro lugar, três eram os gêneros da humanidade, não dois como agora, o masculino e o feminino, mas também havia a mais um terceiro, comum a estes dois, do qual resta agora um nome, desaparecida a coisa; andrógino era então um gênero distinto, tanto na forma como no nome comum aos dois, ao masculino e ao feminino, enquanto agora nada mais é que um nome posto em desonra. (...) Depois de laboriosa reflexão, diz Zeus: "Acho que tenho um meio de fazer com que os homens possam existir, mas parem com a intemperança, tornados mais fracos. Agora com efeito, continuou, eu os cortarei a cada um em dois, e ao mesmo tempo eles serão mais fracos e também mais úteis para nós, pelo fato de se terem tornado mais numerosos; e andarão eretos, sobre duas pernas. Se ainda pensarem em arrogância e não quiserem acomodar-se, de novo, disse ele, eu os cortarei em dois, e assim sobre uma só perna eles andarão, saltitando." (...) Por conseguinte, desde que a nossa natureza se mutilou em duas, ansiava cada um por sua própria metade e a ela se unia, e envolvendo-se com as mãos e enlaçando-se um ao outro, no ardor de se confundirem, morriam de fome e de inércia em geral, por nada quererem fazer longe um do outro. E sempre que morria uma das metades e a outra ficava, a que ficava procurava outra e com ela se enlaçava, quer se encontrasse com a metade do todo que era mulher — o que agora chamamos mulher — quer com a de um homem; e assim iam-se destruindo." (Platão, 1991, p. 56-57). 
Nietzsche, porisso, intensifica suas críticas ao modocomoo cristianismocompreendeuepraticouoamor,cujailusãodependeu, principalmente, dainvençãodeumdeustodo-amoroso,tornadoum espelho para que o ser humano mire a si mesmo. Ora, uma tal tarefa não poderia ser senão ineficaz e contribuir para o desprezo a simesmoquemarcatodamoralidade, dadoqueao serhumanonão estádada a possibilidadedeamarassim,deformadespretensiosae desinteressada,emborataltarefaseja-lheimpostapelamoralcristã,naforma deumprejuízo,cujoresultadoéaculpaeosentimento depecado, de frustraçãoe, nas palavras deNietzsche, de adoecimento e fastio do homem consigo mesmo. O problema, mais uma vez, nãoera serhumano, mas precisamenteoespelhonoqualele se olhava.

É precisamente a crítica a essa imagem de um "Deus todo amor" que será um dos alvos principais de Nietzsche porque, ao desvelar o seu sentido mais maléfico, levaria à inocência do homem: "Como? Um deus que ama os homens, desde que acreditem nele, e que lança olhares e ameaças terríveis a quem nãocrênesse amor? Como? Um amor com cláusulas éo sentimento de um Deus todo-poderoso?(FW/GC,141,KSA3.489). Afilosofianietzschiana,assim, assumiua tarefa dequestionareapontaros prejuízosdo cristianismopara avidae,consequentemente, umnovoconvitede amor à terra.

Ora,para Nietzsche, umatalplenitude seconquistana solidão, ocasião para ocultivodesi, quandoalguém sente a distinção em relaçãoàmassagregária eempenha-seemtornar-se uma obra de arte: "por meio da arte, nos são dados olhos e mãos e, sobretudo, boa consciência, parapoderfazer de nós mesmos um talfenômeno"(FW/GC107,KSA3.464).Fazerdesimesmouma obra dearte significa conquistar uma plena beleza decaráter que possa levar ao mais alto grau de fruição consigo mesmo: " pois uma coisa énecessária: que o homem atinja a sua satisfação consigo" (FW/GC, 290, KSA 3.530). Amando-se a si mesmo por sua bele- 
za,entãooindivíduoestarápreparadoparaentregar-sea outros, não porque ele mesmo necessite fazê-lo como resultado de uma carência,mas precisamenteocontrário,comoresultadodeuma exuberância que quer derramar-se, partilhandouma talbeleza . Adquirir talbeleza é um processoárduo que pode ser resumido em uma virtude que Nietzsche considera essencial, um critériocentralpara a prática doamor: a solidão. Comoumaespécie de asseio, de toalete espiritual, a solidão é o critério desse embelezamento quefazcadaindivíduo elevar-se atéo mais algo degrau do amor a si mesmo. Se a vida em sociedade é sempre uma experiência desujeiraeadoecimento, a solidãoéolugardareconquista da saúde:

Por isso vou para a solidão - a fim de não beber das cisternas de todos. Estando entre muitos, vivo como muitos e não penso como eu; após algum tempo, é como se me quisessem banir de mim mesmo e roubar-me a alma. Aborreço-me com todos e receio a todos. Então o deserto me é necessário, para ficar novamente bom. (M/A, 491, KSA 3.290).

Ora,Nietzschefazda solidãoumelementodecrítica àmoral vigentenoOcidente, queanegouem nomedagregariedade: ${ }^{6} \mathrm{Pau}$ latinamente esclareceu-se, para mim, a mais comum deficiência denossotipodeformaçãoeeducação:ninguémaprende, ninguém aspira, ninguém ensina - a suportar a solidão" (M/A, 4443, KSA 3.270 ), escreveofilósofoemAurora, 443. Isso ocorre porquea virtude moral por excelência, passou a ser o "instinto de rebanho":

o que aqui se julga saber, o que aqui se glorifica com seu louvor e seu reproche, e se qualifica de bom, é o instinto do animal de rebanho homem: o qual irrompeu e adquiriu prevalência e predominância sobre os demais instintos, fazendo-o cada vez mais, conforme a crescente aproximação e assimilação fisiológica de que é sintoma. Moral é hoje, na Europa, moral de animal de rebanho (JGB/BM, 202, KSA 5.124).

E é essa a moral que precisa ser combatida e para a qual é 
preciso que sejam valorizadas novas virtudes, agora não mais produto e promotoras da fraqueza, mas da força da vida:

Permanecer senhor de nossas quatro virtudes, da coragem, do discernimento, da simpatia, da solidão. Pois a solidão é uma virtude, como uma sublime inclinação e ímpeto de asseio, que adivinha que no contato com os homens - 'em sociedade'- as coisas têm que ocorrer de maneira inevitavelmente suja. Toda comunidade - de alguma maneira, em algum lugar, alguma vez - torna comum. (JGB/BM, 284, KSA 5.231).

Não por acaso, o exemploconstante deNietzsche a esserespeitoseriamosgregos: trata-sedaquela "falhanoespelho", provocada por "erros darazão" em relação asimesmo(MA I/HHI, 133, KSA2.126). Enquantoohomemgrego,olhando-senoespelho, viu a si mesmo e a tudo ao redor como belo, criando por isso uma religião de autoafirmação; os cristãos viram em si mesmos muitos defeitos,implementandomedidasquetentavamconsertaressedesgostoconsigomesmos, algo que, afinal, ficounabasedamoralidade, nascida precisamente desta falha do espelho. Os cristãos não se deram conta de que esse desgosto era, na verdade, um "erro da razão" (uma falha no espelho - no limite - e não em si mesmos). Nesse aforismo 133 de Humano, demasiado humano, Nietzsche se pergunta:"comopoderiaoego agirsemego?", colocandoemxeque com isso a base do amor cristão, baseado puramente no altruísmo. Issoporque, noaltodamoralidade, estaria ainvençãode ${ }^{66} \mathrm{um}$ Deustodo amor", queserviu a partir deentãodeparâmetroparao serhumano, quedeveevitaroegoísmoemnomedomais radicalaltruísmo: o homem "secompara comum serquesozinhoécapazde todas as ações altruístas e que vive na contínua consciência de um mododepensardesinteressado: Deus;éporqueolhanesseespelho claro que o seu ser lhe parece tão turvo, tão incomumente deformado"(MAI/HHI, 132,KSA2.125). Nietzscherecordaumafrase deLichtenberg: "éimpossívelsentirpelosoutros,comosecostuma dizer; sentimosapenaspornósmesmos. Afrasesoadura,mas não é, se for apenas corretamente entendida. Não amamos pai, mãe, 
esposa ou filho, mas os sentimentos agradáveis que nos causam" (MAI/HHI, 133, KSA2.126). Em outras palavras, a basede todo amor seria sempreoegoísmo. Nietzsche, porisso,ironiza acrença em um amor não-egoísta:

Aquele está oco e quer ficar cheio, esse está repleto e quer esvaziar-se - cada qual é impelido a buscar um indivíduo que sirva a seu propósito. E este processo, entendido em sua mais alta acepção, é designado com uma palavra nos dois casos: amor - como? O amor deveria ser algo nãoegoísta? (M/A, 145, KSA 3.137)

Além disso, Deus se tornou um princípio negador da solidão,porqueéumacompanhiaonipresente,inventadacomomotivo desegurançae "conforto". Oanúnciodesuamorte,porisso, abre o homem par a sua liberdade, representada por um "estar a sós consigo", um "estar inobservado, desprotegido, irrefreado, não-obsequiado" (M/A, 464, KSA 3.279), justamente o contrário da situaçãoprotagonizadapela divindade, quesecaracterizavacomouma "importunidade celeste", um "inescapável vizinho sobrenatural". Deus, porquetudoama,tudovigiaeprotege,nuncadeixandooser humano de fato sozinho consigo mesmo.

Dessaforma,otipodeamorpraticadoporNietzscheéaquele do grande amor, tomando em conta que essa expressão traduz a inclusãonoconceitodeamor, precisamentedoseucontrário:seem Nietzscheencontramosaideiade "grandearte" (grosseKunststufen -GT/NT, 4, KSA 1.42), "grande saúde" (grosse Gesundheit-FW/ GC 382, KSA 3.637), "grande política" (grosse Politik - MA I/ HHI,481,KSA2.314;JGB/BM,241, KSA5.180), "granderazão" (grosse Vernunft - JGB/BM, 201, KSA 5.122), "grandes homens" (grosse Männer-MA I/HH I, 163, KSA 2.153; ZA, I, Das moscas do mercado, KSA4.65)etc.éporqueoadjetivogrosse (grande)desempenhaumpapeldetransliteração, ou seja, dealteraçãodosentido dosubstantivo ao qual ele se refere. Em outras palavras, o uso do adjetivoaumentativotraduzadinâmicadanovacompreensãose- 
mânticabuscadapor Nietzschecomopossibilidadederepensaro conceito apartirdedentro, numa configuraçãocapazdereunir dois extremos num mesmo requisito teórico-metafórico.

Assim, aofalaremgrandeamor,incluíamosneleoque,tradicionalmente, foi consideradooseucontrário:precisamenteaideia deegoísmo. Todos os atos consideradosamorososealtruístas, para Nietzsche, guardariam esse resquício justo e legítimo de amor a si mesmo. "Oqueéentãooegoísmo?", perguntaNietzscheemumfragmentopóstumo: "O sentimento deprazerna expressão daforça do indivíduo.Ocontrário:osentimentodeprazernarenúnciadoindivíduo. Emgeral, a vidadentremuitoséoprazerforadosindivíduos, entre os indivíduos" (Nachlass/FP 7[149], KSA 7.197). Egoísmoé prazerconsigomesmo, portanto,prazeremsuaprópriaforça,alegria consigomesmo.Arenúnciaasi, aocontrário,comoquerocristianismo, não seria outra coisa senão adoecimento e fraqueza.

Nessecaso, mesmo a invenção de um Deus todo amor, pressuporia oegoísmo. Comoéprópriodametodologiapsicológicapraticadanosegundoperíodo, Nietzschetambémsepergunta sobrea persistênciadosatos amorososaolongodahistória damoral. Para responderàquestão, elefazreferênciadireta osestudosdoseuamigo Paul Rée, em Sobre a origem dos sentimentos morais: "quanto à razãopor quea atos deamor sãomais estimadosqueosoutros, não devido a sua essência, mas a sua utilidade, lembremos as 'investigações sobre a origem dos sentimentos morais' jámencionadas" (MAI/HHI, 133, KSA2.126). Comoé próprio do tipo de procedimentoinauguradopor RéeedesenvolvidoporNietzsche,utiliza-se aquiaideiadaseleçãomoral,inspiradanateoriaevolutiva,na qual a utilidade de um sentimento é que o torna mais comum. Nesse caso, porqueerammaisúteis para obemdacomunidade, os gestos amorososforammaisvalorizadose, aolongodotempo,tornaram-se maiscorriqueiros. Isso, embora ohomemseja ${ }^{66}$ omaismaldosodos animais"comodizafrasedeMalebranchequeservedeepígrafeao livro de Paul Rée. 


\section{Amor como exuberância}

Como resultado do cultivo dessa espécie de egoísmo saudável, oamor passa a servisto por Nietzsche como uma exuberância, opulência,profusãoefartura. TalvezopersonagemdeZaratustra seja aquele que melhor encarnou essa ideia. Já noinício da obra, no seu Prólogo, encontramos o primeiro debate do profeta com o monge da floresta, que representa a tradição cristã, cujo temaéo amor. ParaZaratustra, o amor nãoé apenas um sentimentoindividual, mas um afeto pela própria humanidade, uma espécie de amor coletivo que o faz levar a eles uma doação, uma espécie de presenteparaahumanidade, conquistadanoslongos anos desolidãovividas peloprofetanoaltodesuamontanha. Odiálogoquese estabelecenessaprimeirapartedaobraémuitorevelador: depois de ter vivido dez anos na solidão da montanha, Zaratustra se dá contadequeacumulou "demasiadomel" equeprecisadistribuira suasabedoria, ou seja, partilharoresultadoda suaconquista. Nenhumametáforapoderiasermaisútilparasimbolizaressaquestão do que o sol: como o sol entrega todos os dias o seu calor de forma gratuita, espontânea e sem inveja, pleno de si mesmo, também o profetaquer entregara suaplenitude; comoosolnãoseincomoda com a "felicidade excessiva" (Za/ZA, prólogo, 1, KSA 4.11) que cobrecomseubrilho,Zaratustratambém, comoele, querdeclinar, ou seja, levar a sua luz para outros abismos: "abençoa a taça que quertransbordar,paraqueaáguadelaescorradouradaeportoda parte carregue o brilho do teu enlevo" (Za/ZA, prólogo, 1, KSA 4.11) porquefinalmente, "estataçaquernovamenteseesvaziar".

EssaluzconquistadaporZaratustraérepresentada(deforma crítica ao século XVIII, que teria sido-enganosamente-o século da luz, porque o século da razão) pelo reconhecimento de sua inocência:"MudadoestáZaratustra", dizosantodafloresta, "tornou-seumacriançaZaratustra". Zaratustraconquistaainocência, 
advindadaconclusãodainexistênciadaverdadeúltima,traduzida pela notícia da "morte deDeus". É precisamente a morte deDeus que funda a inocência de Zaratustra e faz com que o seu, seja um amor inocente, porque desprovido de culpa e ressentimento: " $\mathrm{Eu}$ amooshomens". Diantedessaafirmação,osantoresponde: "agora amo a Deus: os homens já não amo. O homem é, para mim, uma coisademasiadoimperfeita.Oamoraoshomensmemataria".Para aquelequeamaa Deus,o puroamor, aperfeiçãoúltima,oshomens nãosãodignos doamor. ParaZaratustra, aocontrário,épelaimperfeição,agorainterpretadacomoum "errodarazão", queoshomens precisam ser libertados para que voltem à inocência desse olhar amoroso sobre simesmo. Responde então o profeta para o santo: "Que fiz eu, falando de amor? Trago aos homens uma dádiva". A grandedádivatrazidaporZaratustra serevelaprecisamentepela ideia de inocência: "mudado está Zaratustra", diz o santo, "tornou-se uma criança Zaratustra". A notícia da "morte de Deus", realidade aprendida no alto da montanha, livra o homem dojogo da culpa, do pecado e do ressentimento que o tornou feio diante do espelho no qual se vê: agora ele recupera a beleza consigo mesmoedenovopoderáamar. Porisso, o anúncionãopoderia ser outro: "eu vosensinooalém-do-homem. O homeméalgo quedeve sersuperado"(Za/ZA,Prólogo,3, KSA4.14). Superar o homemé também superar o desgosto pelo homem; é superar a moralidade da carência e da falta; é superar aquele tipo de amor nascido da náusea.Anunciaroalém-do-homeméanunciarograndeamorque ohomemprecisareconquistaremrelaçãoasimesmo. Sobretudo,o Übermensch é um produto da recuperação do amor do homem por si mesmo. Como se lê não aforismo 134 de Humano, demasiado Humano, a superaçãodocristianismodarialugarparaumnovotipo de sentimento amoroso, porque o cristão

foi levado ao sentimento de autodesprezo por alguns erros, isto é, por uma interpretação falsa, não científica, de suas ações e sentimentos, deverá perceber com assombro que esse estado de desprezo, de remorso, de desprazer, não persiste, e que ocasionalmente tudo isso é afastado de sua 
alma e ele se sentir livre corajoso novamente (MA I/HH I, 134, KSA 2.128)

Eis anecessidadetrazida peloanúnciodeZaratustra:superarafalhanoespelhoésobretudorecuperaroprazerconsigomesmo, "obemestarcoma própriaforça", parafinalmenteanunciar: "o homem sente que de novo ama a si mesmo" (MA I/HH I, 134, KSA 2.128). Um tal amor é descrito como um sentimento de "divinação": o homemagora, afinal, vêtudo como sefosseele mesmo umDeus, taloseucontentamentoconsigomesmo. Masoamorque reconheceemsimesmolheéainda algoestranhoeaparentemente pecaminoso caso a fonte fosse ele mesmo. Por isso, insiste em reconhecernessesentimentodeinteireza, aindaumelementodivino:

\begin{abstract}
agora interpreta suas experiências de modo a lhes introduzir a bondade divina: tal evento lhe parece pleno de amor; aquele outro, uma indicação benfazeja; um terceiro, e a sua própria disposição alegre, demonstração de que Deus é piedoso. Se antes, no estado de pesar, interpretava falsamente suas ações, agora faz isso com suas vivências; apreende o seu consolo como efeito de uma força externa; o amor com que no fundo ama a si mesmo, aparece como amor divino; aquilo que chama de graça e prelúdio de redenção é, na verdade, graça para consigo em redenção de si mesmo. (MA I/HH I, 134, KSA 2.128)
\end{abstract}

Trata-sedeumanovapsicologia, queescondeque,nofundo, ohomemama asimesmo, mas continuaainda dependentedaideia deumDeus, porquenãosesentemerecedor dessaautoestima. Ele ainda não está libertado de todo das amarras. Ele ainda não se tornou aquilo que Zaratustra veio anunciar. Mesmo amando a si mesmo, mesmo provando essa força que lhe é própria, o homem prefere ainda acreditar que tudo não passa de um "raio de graça".

Ora, afirmar o amor a simesmo comoalgo desejável, coloca o pensamento de Nietzsche mais uma vez em rota de colisão com a ideia de abnegação de si, uma das forças motrizes da moral da compaixão.Transformadaemvirtude, paraNietzscheacompaixão não passaria de uma fraqueza e conduz à negação da vida: 
Em termos bem gerais, a compaixão entrava na lei da evolução, queéa leidaseleção.Conservaoqueémaduroparaodesaparecimento,pelejaa favordosmalogradosdetodaespéciequemantém vivos, dáàvidamesma umaspectosombrioequestionável. Ousou-sechamaracompaixãouma virtude (- em toda moral nobre é considerada fraqueza -); foi-se mais longe,fez-sedela $a$ virtude, o soloeorigemdetodas as virtudes-apenas, é verdade, e não se deve jamais esquecer, do ponto de vista de uma filosofia que era niilista, que inscreveu no seu emblema a negação $d a$ vida (AC/AC, 7, KSA 6.173).

Fazendo referência à "lei da evolução" e à "lei da seleção", Nietzscherecupera mais uma vez as teses de Paul Rée, para quem a persistência dacompaixãofoi resultado deumprocessoseletivo daquiloqueeraconsideradomais adequadopara avidasocial.Com isso, a moral da compaixão, seja em sua raiz cristã, seja schopenhauriana, remeteà celebraçãodoaltruísmoe aocombatea qualquer espécie de autofruição. Esse tipo de amor que exige que os outros amem um indivíduo quenãoama a simesmo, édenunciado porNietzschecomoumaespéciedeironiaedecontradiçãodocristianismoesua estratégia;baseadonas "observaçõespsicológicas" inauguradasemHumano, demasiadohumano éprecisodemonstrar como nas suas bases encontra-se, embora não revelado, o desejo deautofruição: "Odesejoúnicodeautofruiçãodoindivíduo(junto comomedodeperdê-la) satisfaz-seemtodas ascircunstâncias, aja o ser humano como possa, isto é, como tenha de agir: em atos de vaidade, devingança,prazer, utilidade,maldade, astúcia,ouem atos de sacrifício, de compaixão, de conhecimento"(MA I/HH I, 108, KSA 2.107).

Emoutraspalavras, paraNietzsche, quandoseacreditaem umamor puro, ou seja, semegoísmo, somos vítimas denosso“autoengano":

E credes, vós que tanto glosam e elogiam "o esquecimento de si mesmo no amor", "o abandono do eu na outra pessoa", que issoé algo essencialmente diferente [do que se chama de autoengano]? Assim, pois, alguém rompe o espelho, se imagina transferido a uma pessoa a 
quem admira, e entãogoza de uma nova imagem de seu eu, ainda que a designe com o nome de outra pessoa e todo esse processo não há de ser autoengano, egoísmo, vós, extravagantes devósmesmos!(MAII/HHII; OS, 37, KSA 2.397)

\section{Amor como liberdade de tornar-se o que se é}

Outro aspecto que deriva dos dois anteriores no tratamento do amor por parte de Nietzsche diz respeito à sua relação com a ideia de liberdade. Obviamente tal conceito se distancia do seu uso tradicional, para expressar aquilo que está incluído na noção de espírito livre: aquele que cria os próprios valores e tem capacidade de impô-los sobre si mesmo, independente das amarras da tradição. A noção nietzschiana de liberdade está associada à noção de disputa e combate e à ideia de resistência. O homem livre é o homem do confronto, que passou por sua própria solidão e alcançou a reverência por si mesmo:

Liberdade significa: os instintos viris, alegres na guerra e na vitória se apoderaram dos outros instintos - por exemplo, o instinto de 'felicidade'. O homem que se tornou livre e, muito mais ainda o espírito que se tornou livre pisa sobre o modo de ser desprezível do bem-estar, com o qual sonham o comerciante, cristão, a vaca, a mulher, o inglês e outros democratas. $\mathrm{O}$ homem livre é guerreiro. - A partir de que critério se mensura a liberdade dos indivíduos, assim como dos povos? A partir da resistência que precisa ser superada, a partir do esforço que custa para permanecer em cima. (GD/ CI, Incursões de um Extemporâneo, 38, KSA 6.139).

Essa ideia exige que o amor seja compreendido como liberdade plena para que cada indivíduo se torne aquilo que é, implementado todas as medidas para que isso se efetive: escolhas, experiências, vivências. Por isso, nessa perspectiva amorosa, estão incluídas as noções de rompimento, distanciamento e infidelidade, como aspectos próprios daqueles que 
amam de forma radical, a tal ponto que pretendem - e exigem, precisam disso - que o outro continue sendo o que é. Em um aforismo de Humano, demasiado humano, Nietzsche é muito direto sobre esse tema: falando da fidelidade, ele afirma que "não existe nenhuma lei, nenhuma obrigação dessa espécie", acrescentando que "temos de nos tornar traidores, praticar a infidelidade, sempre abandonar nossos ideais. Não passamos de um período a outro da vida sem causar essas dores da traição e sem sofrê-las também" (MA I/HH I, 629, KSA 2.354). Essa, aliás, é a tarefa do próprio pensador: “o pensador deve, de quando em quando, afugentar as pessoas que ama (não serão exatamente aquelas que o amam), para que mostrem seu ferrão e sua maldade e parem de seduzi-lo. (M/A, 479, KSA $3.285)$.

Talperspectiva diferencia-sedaideia associadapor Nietzscheao amormoderno, queselimita àideia de posseepropriedade, tal como aparece, por exemplo, no aforismo $14 \mathrm{de} A$ Gaia Ciência, cujo título é As coisas que chamamos de amor e no qual o amor é tratado como uma espécie de cobiça, um "mesmo impulso que recebe dois nomes"4. Nietzsche pergunta: "nosso amor ao próximo-não é ele uma ânsia por nova propriedade?"'. Ora, a posse de um ser não demora a torná-lo algo enfadonho, porque toda posse logosetorna algo "velho", deixandodedespertarinteresse.Como posse o outro se torna aquilo que nós mesmos somos; como nossa posse, ele deixa de ser ele mesmo para corresponder àquilo que nósmesmos esperamos dele.E, comoafirma Nietzsche: "asposses sãodiminuídaspelaposse". Tendemos atransformar "algonovoem nós mesmos - precisamente a isso chamamos possuir. Enfadar-se de uma posse é enfadar-se de si mesmo". Para Nietzsche, essa éa experiênciadoamorsexual, ondeserevela"maisclaramentecomo ânsia depropriedade: oamantequer aposseincondicionaleúnica

4. Piazzesi (2010) demonstrou como esse aforismo serve como indicação do procedimento genealógico em Nietzsche, a começar por uma crítica ao preconceito presente na linguagem.

Cad. Nietzsche, Guarulhos/Porto Seguro, v.41, n.3, setembro-dezembro $2020 \mid 93$ 
dapessoa desejada, quer poder ser amado unicamente, habitandoedominandoa outraalmacomoalhosupremoeabsolutamente desejável" (FW/GC, 14, KSA3.386). Eis a experiência do matrimôniomoderno,noqualafidelidadeadquiriu umvalorcentral: a fidelidadenão seria outra coisa senãoo compromisso em torno de umaposse.ParaNietzsche, issosignifica"excluir todoomundode um precioso bem, de uma felicidade efruição; se considerarmos que o amante visa o empobrecimento e a privação de todos os demais competidores" (FW/GC, 14, KSA3.386). Para Nietzsche, a concretizaçãodessetipode sentimento sedáprecisamentenamulher:longedequererproblematizaraquium assuntotãopolêmico e tão complexo, que por si mesmo merece uma abordagem muito mais aprofundada,basta-nos apontarparaoargumentoqueleva Nietzsche a afirmar sua perspectiva (considerada, sob os nossos olhos, obviamente,machista).Paraele, "amulherquersertomada e aceita como posse, quer ser absorvida na noção de 'posse', de "possuído"” (FW/GC, 363, KSA 3.610). Na medida em que esse sejaoelementofundadordosmatrimôniosmodernos, aocriticá-lo, Nietzschecriticaa estruturaquedeulegitimidadereligiosa, moral e social ao amor sexual e demonstra como a sua prática esconde a buscapelodomíniodoseramadoe,tambémaqui,estaríamosdiante do egoísmo e da cobiça.

Em um fragmento da época de elaboração de Humano, demasiado humano, Nietzsche diferencia o amor da amizade, precisamente sob o critério da ideia de posse. Para ele, "o amor se situa muito abaixo da amizade por ele aspira à posse exclusiva, enquantoalguémpodeterváriosbonsamigos, eesses, porsuavez, tornarem-seamigos entresi."'(Nachlass/FP18[44], de1876,KSA 8.326).Alémdisso, asconsiderações desenvolvidasnoaforismo 14 deAgaiaciência terminamporuma afirmação,nomínimo,paradoxal:comoalternativaa esseamorpossessivo, quenega aliberdade do outro em ser quem ele é, o filósofo anuncia a amizade como um amor de tipo superior. "Bem que existe no mundo, aqui e ali, 
uma espéciedecontinuaçãodoamor, na quala cobiçosaânsiaque duas pessoas têm uma pela outra deu lugar a um novo desejo e cobiça, a uma elevada sede conjunta de umideal acima delas: mas quem conhece tal amor? Quem o experimentou? Seu verdadeiro nomeéamizade." (FW/GC, 14, KSA3.386). Não só a amizadeestá contrapostaaoamorpossessivo,como,pormeiodessareferência, Nietzscheretomaum sentimentoassociadoaomundogrego, para servirdeantídotocontra amodernidade. Na amizade, assim, osindivíduosestariamnãoembusca daposseumdooutro, masdealgo superioraosdois: aafirmaçãodavida.Issoporque, paraNietzsche, a amizadé ó nome de um sentimento no qual cada um podecontinuar sendo/tornando-se quem é.

Se no amor matrimonial o amante é objeto de uma posse, a amizadeéo sentimento no qualexige-se quenenhum dos dois passe para o lado do outro, mas, bem a o contrário: é preciso que o amigo saibaguerrearequeelepossamanter-secomoumadversário, resistindo, pois é assim que se torna útil para o crescimento das forças vitais. Talperspectiva,jádesenvolvidapornósemoutrostrabalhos, coloca a solidão e, depois, a inimizade, como critérios da amizade: "sesequiser terumamigo,éprecisotambémguerrearporele;epara guerrearémisterpoder serinimigo"(Za/ZA, Doamigo,KSA4.72). Aguerra, aqui, podeserinterpretadacomoaresistênciaprópriadaqueles que querem se manter livres, íntegros e plenos de si mesmo:

"Sê ao menos meu inimigo!" Assim fala o verdadeiro respeito, que não ousa pedir amizade. Se se quer ter um amigo, então também se deve querer fazer guerra por ele; e para fazer guerra, é preciso poder ser inimigo. Mesmo na pessoa do amigo, se deve honrar o inimigo. És capaz de chegar-te muito perto do teu amigo, sem te passares para o lado dele? Deves ter no teu amigo o teu melhor inimigo. É quando o contrariasquedevesestarmaispróximodelecomocoração(Za/ZA,Do amigo, KSA 4.72).

A ideia de guerra está ligada, assim, à resistência que cada umdeveter em relaçãoaos demais. Esseaspectoétãoimportante, 
queservemesmopara adefiniçãodeamor-mesmooamorentreos sexos: "Houveouvidos para escutarminhadefiniçãodoamor?Éa única digna de um filósofo. Amor-em seus meios a guerra, em seu fundooódiomortaldos sexos"(EH/EH, Porqueescrevotãobons livros, 5, KSA 6.305).

Como se nota, portanto, a amizade é a alternativa afetiva ao amor possessivo e se apresenta como um sentimento de plenitude, no qual estão incluídas as ideias de infidelidade, distanciamento e traição, já que essas seriam consequências necessárias quando aquele que se ama continua a construir o seu destino sem passar para o lado do outro: "não é o modo como um alma se aproxima de outra, mas em como se afasta dela que reconheço seu parentesco e relação com a outra" (MA II/HH II, OS, 251, KSA 2.489). Talvez a passagem que melhor expresse essa experiência apareça em $A$ gaia ciência, 279. Nela, Nietzsche escreve, em tom pessoal, sobre a sua relação com Paul Rée. O título do aforismo é Amizade de astros:

Nós éramos amigos e nos tornamos estranhos um para o outro. Mas está bem que seja assim, e não vamos nos ocultar e obscurecer isto, como se fosse motivo de vergonha. Somos dois barcos que possuem, cada qual, seu objetivo e seu caminho; podemos nos cruzar e celebrar juntos uma festa, como já fizemos - e os bons navios ficaram placidamente no mesmo porto e sob o mesmo sol, parecendo haver chegado a seu destino e ter tido um só destino. Mas então a todo-poderosa força de nossa missão nos afastou novamente, em direção a mares e quadrantes diversos, e talvez nunca nos vejamos de novo - ou talvez nos vejamos, sim, mas semnosreconhecermos:osdiferentesmaresesoisnosmodificaram!Que tenhamos de nos tornar estranhos um para o outroé a lei acima de nós: justamenteporissodevemosnostornartambémmaisveneráveisumpara ooutro!Justamenteporissodeve-setornarmaissagradoopensamentode nossaantigaamizade!Existeprovavelmenteumaenormecurvainvisível, uma órbita estelar em que nossas tão diversas trilhas e metas estejam incluídas como pequenos trajetos - elevemo-nos a esse pensamento! Mas nossa vida é muito breve e nossa vista muito fraca, para podermos ser mais que amigos no sentido dessa elevada possibilidade. - E assim vamoscreremnossaamizadeestelar, aindaquetenhamosdeserinimigos na Terra (FW/GC, 279, KSA 3.523). 
A beleza da passagem é complementada com a força argumentativa queliga a amizade àquiloque, geralmente, estariafora doamor: orespeitoàs escolhas, necessidadesenaturezadooutro. Issotambémapareceemumfragmentopóstumode1878:“Amigos. Nadanosobriga,mas nosgostamos reciprocamenteatéopontode que um favorece o caminho tomado por outro ainda quando seja diametralmenteopostoaoseu(Nachlass/FP27 [95], KSA8.502)". $\mathrm{O}$ amigo não se exonera que seja ele mesmo, portanto, inclusive quando e se tal cois a exigir que o afeto entre ambos seja altercado pela distância. Umaideia que aparece em outrofragmento muito sugestivo de A gaia ciência:

Deixamosaterrafirmeeembarcamos!Queimamosaponte-maisainda, cortamostodolaçocomaterraqueficouparatrás!Agoratenhacautela, pequenobarco!Juntoavocêestáooceano,éverdadequeelenemsempre ruge, eàs vezes se estende como seda euroe devaneio debondade. Mas virão momentos em que você perceberá que ele é infinito e que não há coisamaisterrívelqueainfinitude. Oh, pobrepássaroquesesentiulivre e agora se bate nas paredes dessa gaiola! Ai de você, se for acometido de saudade da terra, como se lá tivesse havido mais liberdade-e jánão existe mais "terra"! (FW/GC, 124, KSA 3.480).

Aexperiênciadorompimentoé, portanto,dolorosaeperigosa,masimprescindível para queosindivíduos construamrelações afetivasplenas. Essaéa condiçãomesmodanobreza,nascidadessa prática afetiva nova do grande amor, cujo símbolo é a amizade: "orefinamentonoconceito de amizade, umacertanecessidadede terinimigos (como canais deescoamento, por assimdizer, para os afetos deinveja, agressividade, petulância-nofundo,parapoder ser bem amigo)" (JGB/BM, 260, KSA 5.208). Nota-se, com isso, queNietzsche associa o amor (naforma da amizade)à plena liberdade daquele que adquire, por coragem, o direito de continuar a serqueméou,como sugerea ricafórmula quedá subtítuloaolivro autobiográfico de Nietzsche, tornar-se quem é. 


\title{
V. Considerações finais
}

Aanálisedoamor,comoosentimentomoral por excelência, fornece uma espécie de chave de entrada em muitos campos teóricos sobre os quais a filosofia nietzschiana se ergue, seja porque favoreceumacompreensãodoseuprocedimentodecríticaàmetafísica, sejaporqueexpressa acrítica dofilósofoàtradição socrático-platônica, judaico-cristãemoderna.Dessaforma,emboraaparentementesecundárionocorpus teórico, otema ofereceinúmeras possiblidades deanálise, tornando-seextremamentericodoponto de vista teórico e - por que não dizer - biográfico.

Nietzsche, assim, nãoapenasdesenvolveumanovaperspectiva deanálisedosentimentoamoroso, comosobretudo, umanova forma de vivência, articulada com oconvite de Zaratustra para a fidelidadeàterra, aocorpoeàscoisashumanas, demasiadohumanas. Essa nova espécie de amor, por isso, traduz a tarefa de construçãodenovosvalores, pelaviadosconceitosde "eternoretorno", "amor fati" e "transvaloração dos valores".

Three Variations on Love in Nietzsche's Philosophy

\begin{abstract}
This articleaimsto analyzethreeaspects of the theme ofloveinFriedrichNietzsche'swork. Forthat,itstartsfromtwo assumptions: [1] the feeling of love must be understood as part of the project of criticism of metaphysics and theidealisms present in morals, religion and art; and as a consequence, [2] as a critique of thenotions of lovethatrefertotheSocratic-Platonic, Judeo-Christianandmoderntradition. Thethreeaspectsderived from it, show that love in Nietzsche [1] is not lack, [2] nor self-denial, [3] nor is it based on the idea of possession; quite the contrary, theoppositelink, [1] loveis exuberance, [2] depends on the enjoyment of oneself and [3] is based on self-differences andnaturalinequalitiesbetweenindividuals. Suchananalytical procedure comes to the affirmation of friendship as a superior love, whose content refers to a feeling of noble men, precisely what could be called, in Nietzsche, great love.
\end{abstract}

Keywords:love,selfishness, bigLove,self-affirmation,loneliness.

$98 \mid$ Cad. Nietzsche, Guarulhos/Porto Seguro, v.41, n.3, setembro-dezembro 2020 


\section{Referências}

CHAVES, Ernani. A arte das paixões: Nietzsche, leitor de Prosper Mérimée. Estudos de Nietzsche, v. 4, n. 1, 2013.

NIETZSCHE, F. Sämtliche Werke. Kritische Studienausgabe in 15 Bänden. Herausgegeben von Colli und Montinari. Berlin/ München: Walter de Gruyter/DTV, 1988.

. Crepúsculo dos ídolos (ou como filosofar com o martelo). 2 ed. Trad. de Marco Antônio casanova. Rio de Janeiro: Relume Dumará, 2000. (Conexões, 8).

. Humano, Demasiado Humano. Um livro para espíritos livres. Trad. de Paulo César de Souza. São Paulo: Cia. das Letras, 2000.

- A Gaia Ciência. Trad. de Paulo César de Souza. São Paulo: Cia. das Letras, 2002.

. Assim falou Zaratustra. Um livro para todos e para ninguém. Trad. de Mário da Silva. Rio de Janeiro: Civilização Brasileira, 2006. . Ecce homo. Como alguém se torna o que é. Trad. de Paulo César de Souza. São Paulo: Cia. das Letras, 2008.

. Humano, Demasiado Humano II. Trad. de Paulo César de Souza. São Paulo: Cia. das Letras, 2008.

PIAZZESI, Chiara. "Was Alles Liebe genannt wird" ("Tudo o que é chamado de amor"). Cadernos Nietzsche, n. 27, p. 73-115, 2010.

PLATÃO. O banquete. In: Platão; Diálogos (Os pensadores). Seleção de textos de José Américo Motta Pessanha; tradução e notas de José Cavalcante de Souza, Jorge Paleikat e João Cruz Costa. 5. ed. São Paulo: Nova Cultural, 1991. 